\title{
Mauro Mamani Macedo, M. (2017). Sitio de la tierra. Antología del vanguardismo literario andino. Lima: Fondo de Cultura Económica
}

El vanguardismo literario peruano, desarrollado durante las décadas de 1920 y 1930, goza de un amplio concierto de voces diversas conformado por poetas, narradores y ensayistas, quienes, en su mayoría, provienen de las capitales del interior del país, específicamente de las regiones andinas (Arequipa, Huancayo, Puno, La Libertad, Cajamarca). Este rasgo resulta significativo puesto que aquellos autores desempeñaron un rol fundamental dentro de la producción hemerográfica de la época, en un afán por exponer sus perspectivas literarias, políticas y culturales, además de sus propias creaciones tanto en poesía como en prosa. El Boletín Titikaka (1926-1930), las revistas Puno Ilustrado (1919), Kosko (1924-1925, 1932), Kuntur (1927-1928), Chirapu (1928), los periódicos La Voz del Obrero (1914-1918) y La Voz de Huancayo (1912-1930) son algunos ejemplos de los órganos de difusión vanguardista más relevantes en el contexto provinciano; en ellos se puede identificar el constante diálogo que mantuvieron sus colaboradores, así como los vínculos temáticos, estilísticos e ideológicos entre ellos y la herencia que asumen de los escritores de otras tradiciones literarias (Pound, Joyce, Whitman, etc.). Asimismo, las revistas vanguardistas publicadas en Lima, como Amauta (1926), Flechas (1924), Guerrilla (1927), Jarana (1927) y ABCDario (1929-1930), estuvieron dirigidas por provincianos, lo cual evidencia un sólido proceso de descentralización cultural, histórica y política.

Si bien la crítica literaria ha dedicado su atención a los poetas César Vallejo, Gamaliel Churata, Alejandro Peralta y Carlos Oquendo de Amat, desmotiva admitir que los estudios críticos sobre los demás representantes vanguardistas son escasos. Puesto que muchos de ellos fueron rápidamente olvidados, se desmereció su calidad estética y su valor cultural e incluso sus producciones literarias no se conservaron ni reeditaron, por lo que cotejarlas es una ardua labor. El reconocido 
docente e investigador Mauro Mamani Macedo (Arequipa, 1969) advierte este lamentable suceso e intenta rescatar a estas figuras. Para ello ha realizado una diligente tarea seleccionando textos cuyos principales méritos se funden en la instauración de una poética autónoma de aliento andino que, sin embargo, asimile las renovaciones formales y temáticas que la vanguardia latinoamericana propuso, como la recepción de la modernidad.

Así, la antología preparada por Mamani Macedo se estructura en cuatro secciones: poesía, prosa, ensayos y correspondencias, precedidas por un estudio introductorio de su autoría que contextualiza histórica, social y políticamente la vanguardia andina en tanto corriente literaria tensa, de producciones heterogéneas y experimentales, cuya influencia en la literatura peruana posterior es aún vigente y que responde a los acontecimientos locales e internacionales en los que se inscribe, como las migraciones internas en nuestro país y las externas hacia España, Francia, Argentina, Bolivia y México, la fundación del APRA, el triunfo de la revolución socialista en Rusia y la difusión de dicha prédica por Mariátegui, la Revolución mexicana, la Primera Guerra Mundial, la reforma universitaria en Argentina, etc. (24-25). En efecto, existe una indisociable correlación entre lo estético, lo ideológico y lo político en el campo literario peruano, como puede observarse en los manifiestos, ensayos, poemas y cuentos publicados en las revistas y periódicos de aquellas décadas. Del mismo modo, señala que 1926 es el año fundacional de esta corriente, pues se publican Ande, de Alejandro Peralta, y Falo, de Emilio Armaza, poemarios vanguardistas en su diseño y espíritu.

La primera sección reúne a veintiséis poetas, entre los que destacan Armaza, Churata, Guillén, Hidalgo, Parra del Riego, Vallejo; no obstante, también se incluye a Emilio Vásquez (1903-1987) y Alberto Mostajo (1896-1984), figuras ausentes en las antologías previas dedicadas a la vanguardia peruana. El segundo apartado muestra textos de siete escritores mencionados en la anterior sección (Chabes, Churata, Delmar, Hidalgo, Oquendo de Amat, Peralta Vásquez y Varallanos). En el tercer apartado se reactualiza el debate que estos creadores fomentaban acerca de la originalidad vanguardista en nuestro país, además de 
la reflexión en torno a su propio hacer artístico y el de sus pares, representados en ocho ensayos: "Septenario" (Churata, pp. 297-299); "Nuestro vanguardismo" (Mercado, pp. 300-302), "nueva crítica literaria” y "Alberto Hidalgo. Los sapos y otras personas" (Oquendo de Amat, pp. 303-304; 305), "Hacia nuestra propia estética” (Pavletich, pp. 306-311), "El uno y vario del arte vanguardista" (Peralta Vásquez, pp. 312-313), “Contra el secreto profesional” (Vallejo, pp. 314-318) e "Inventario de vanguardia" (Bolaños, pp. 319-331). En esa línea, la cuarta sección presenta nueve epístolas de Churata dirigidas a Mariátegui, Peralta Vázquez y Eguren, además de dos cartas de Vallejo enviadas a Chávez Aliaga y Mariátegui, y una de Hidalgo destinada a este último.

Es precisamente en estos dos últimos apartados donde se plantean polémicamente las posturas que dirigen la poesía y prosa vanguardistas: tal es el caso de Churata, quien cuestiona los "siete logos" vallejianos que acusan arbitrariamente a la literatura latinoamericana como una simple imitadora de la europea (p. 299); por su parte, Mercado afirma que la vanguardia "entraña un extenso UNIVERSALISMO en el pensamiento i la práctica del nuevo hombre que la encarna" (p. 301), dando paso a la expresión de emociones de trasfondo social, lo cual concuerda con la perspectiva de Pavletich, que ensalza el cultivo de una estética vernácula en la poesía nacionalista de Alejandro Peralta (p. 309) y la preocupación social vinculada con una síntesis de las estéticas europeas en la lírica de Serafín Delmar (p. 311); a su vez, esta postura coincide con la de Ántero Peralta Vásquez, quien exhortaba que "formemos NUESTRA ESTÉTICA, con el barroco de nuestro suelo y el aliento de nuestra raza" (p. 312). En suma, las dos primeras secciones creativas del libro se complementan formidablemente con los ensayos y las cartas, dado que revelan las corrientes de pensamiento y filiaciones artísticas que los creadores vanguardistas profesaban; sin duda, se trata de un acertado criterio selectivo por parte de Mamani Macedo.

En su conjunto, Sitio de la tierra. Antología del vanguardismo literario andino es un valioso esfuerzo por acercar al público interesado las creaciones y reflexiones literarias de aquellos escritores injustamente relegados por la crítica peruana; 
más allá de ello, el libro pretende fomentar el estudio de las obras vanguardistas andinas, así como la reedición de las mismas, propósitos que, sin duda, podrán concretarse de manera progresiva. Saludamos cordialmente el cuidado de esta importante publicación, la conservación de las versiones originales de los textos y la inestimable bibliografía sugerida. Finalmente, nos sumamos a los nobles objetivos que motivaron su edición y auguramos la juiciosa recepción del público lector.

\section{Gloria Pajuelo Milla}

Universidad Nacional Mayor de San Marcos

Contacto: gloria.pajuelo@unmsm.edu.pe

https://orcid.org/0000-0001-8267-0080 